\title{
Effects of a Multikinase Inhibitor Motesanib (AMG 706) Alone and Combined with the Selective DuP-697 COX-2 Inhibitor on Colorectal Cancer Cells
}

\author{
Tijen Temiz Kaya ${ }^{1}$, Ahmet Altun ${ }^{1}$, Nergiz Hacer Turgut ${ }^{2 *}$, Hilmi Ataseven ${ }^{3}$, \\ Gokhan Koyluoglu ${ }^{4}$
}

\begin{abstract}
In the present study, we investigated the effects of motesanib (AMG 706), a multikinase inhibitor alone and in combination with DuP-697, an irreversible selective inhibitor of COX-2, on cell proliferation, angiogenesis, and apoptosis induction in a human colorectal cancer cell line (HT29). Real time cell analysis (RTCA, Xcelligence system) was used to determine the effects on colorectal cancer cell proliferation. Apoptosis was assessed with annexin $\mathrm{V}$ staining and angiogenesis was determined with chorioallantoic membrane model. We found that motesanib alone exerted antiproliferative, antiangiogenic and apoptotic effects on HT29 colorectal cancer cells. Combination with DUP-697 increased the antiproliferative, antiangiogenic and apoptotic effects. Results of this study indicate that motesanib may be a good choice in treatment of colorectal tumors. In addition, the increased effects of combination of motesanib with DuP-697 raise the possibility of using lower doses of these drugs and therefore avoid/minimize the dose-dependent side effects generally observed.
\end{abstract}

Keywords: Colorectal cancer - motesanib - multikinase inhibitor - COX-2 inhibition

Asian Pac J Cancer Prev, 17 (3), 1103-1110

\section{Introduction}

Colorectal cancer (CRC) is a common solid tumor and it is a leading cause of cancer related death especially in developed countries (Center et al., 2009). About 500,000 deaths are reported per year worldwide due to CRC. Environmental factors, dietary habits, inflammatory bowel disease, age, male sex, and hereditary syndromes are a higher risk in the development of this disease (Chu, 2012). Improvements in screening and staging and also advances in surgery and therapy have enhanced the survival of patients. However CRC is still an important cause of cancer related death. Research groups are focused on understanding the risk factors, molecular biology, and genetics of CRC and also developing new drugs and drug combinations for the management of this deadly disease (van de Velde et al., 2014).

Uncontrolled growth of the tumor and metastasis are main causes of death in patients with cancer. Angiogenesis plays a critical role in the progression of cancer and many proangiogenic factors are involved in this process. Therefore inhibiting tumor neovascularization by inhibiting the activity of these proangiogenic factors has been important for cancer treatment. Angiogenesis is mediated by interaction of multi factors including cytokines and angiogenic growth factors such as vascular endothelial growth factor (VEGF), platelet-derived growth factor (PDGFR) and basic fibroblast growth factor (bFGF) (Paudyal et al., 2014). In primary tumors increase in angiogenesis relates with poor prognosis and recurrence of the disease. The importance of VEGF which is one of the major proangiogenic factors has been documented in CRC progression (Bektas et al, 2014). VEGF is an attractive target for treatment as it is overexpressed in a wide range of tumor types including CRC (Hohla et al., 2014).

Motesanib (AMG 706) is a small molecule inhibitor of VEGF receptors (VEGFR) 1, 2, and 3, platelet-derived growth factor receptor (PDGFR), and stem cell factor receptor (c-Kit) which is administered orally (Rosen et al., 2007). Motesanib has clinical advantage compared to bevacizumab, because of its wide mechanism of action with inhibition of VEGF targets. Motesanib has been investigated in different xenograft tumor models including non -small cell lung cancer, breast cancer, and thyroid cancer both alone and in combination with chemotherapy which these studies showed decrease in tumor growth and also tumor blood vessel density. (Coxon et al., 2009; Coxon et al., 2012a; Coxon et al., 2012b). Motesanib has also shown antitumor activity in phase 1 and/or phase 2 studies in solid tumors including ovarian, fallopian tube and primary peritoneal carcinomas, metastatic breast cancer, thyroid cancer, and nonsquamous non-small-cell 
lung cancer (Lu et al., 2010; Blumenschhein et al., 2011; De Boer et al., 2012; Schilder et al., 2013). Recently, a phase $1 \mathrm{~b}$ study has been performed to determine the safety and efficacy of motesanib alone or combined with panitumumab plus chemotherapy in patients with metastatic CRC (Tebbutt et al., 2015).

Cyclooxygenase-2 (COX-2) contributes to disease processes, including cancer and inflammation. Many studies have shown that cyclooxygenase-2 (COX-2) is highly expressed in different types of malignant and premalignant diseases (Qui and Qui, 2015; Saraiya et al., 2015; Shimizu et al., 2015). Also COX-2 overexpression is well-established in CRC ( $\mathrm{Li}$ et al., 2014). It has been shown that overexpression of COX-2 contributes to carcinogenesis by inducing the production of VEGF, thus enhancing angiogenesis. As well, stimulating cell proliferation and inhibiting apoptosis. COX-2 decreases the production of antiangiogenic cytokine interleukin-12 and also elevates metalloprotein levels that improve the invasion of tumor vessels (Ohno et al., 2007; Kim et al., 2011). Epidemiological studies demonstrate a decline in the incidence of many types of cancer in long-term users of nonsteroidal anti-inflammatory drugs (NSAIDS) (Wong and Chan, 2007; Salinas et al., 2010; Cui et al., 2014). Also it has been shown that regular usage of NSAIDS and COX-2 inhibitors reduce the mortality for sporadic CRC (Steinbach et al., 2000). The side effects of selective COX2 inhibitors especially their cardio toxic effect leads to important concerns for their use in cancer prevention and treatment. However their anticancer effect may be through COX-2 independent mechanisms (Ma et al., 2002; Wei et al., 2004) and selective targeting of downstream effectors may avoid the cardiovascular effects while maintaining antitumorigenic properties (Cathcart et al., 2012). The COX-2 independent anti-cancer effects are needed to be investigated further.

DuP-697 (5-bromo-2-(4-fluorophenyl)-3[4-(methylsulfonyl) phenyl]-thiophene), is a slow, time dependent selective COX-2 inhibitor and it is a member of the vicinal diaryl heterocycles like other selective agents, rofecoxib and celecoxib. Some studies suggest that the anti-proliferative effect of DuP-697 may be exerted via the induction of apoptosis and that this was associated with up-regulation of caspases 3, 8 and 9 (Peng et al., 2008; Agarwal et al., 2013).

Up-regulation of COX-2 and various growth factors like VEGF have been detected together. Previously it has been shown that COX-2 effects angiogenesis via the release of VEGF and prostaglandin E2 (PGE2). The elevation in COX-2 protein expression may increase the production PGE2, resulting in an autocrine or paracrine manner that increases expression of VEGF to activate distinct signaling pathways (Chu et al., 2003; Salimi et al., 2012). Inhibiting COX-2 activity selectively has been shown to inhibit proliferation of endothelial cells, induction of apoptosis and to inhibit angiogenesis (Yazawa et al., 2005; Ninomiya et al., 2012; Kim et al., 2015).

Based on these data, the objective of this work presented here was to investigate the antitumor effect of multikinase inhibitor motesanib on CRC alone and in combination with a selective COX-2 inhibitor DuP-697 with a hypothesis that combining a multikinase inhibitor and a selective COX-2 inhibitor may provide a better inhibition for tumor growth by getting over resistance to single pathway inhibition and using lower doses may prevent and/or reduce the adverse effects.

\section{Materials and Methods}

Motesanib was purchased from Selleck Chemicals LLC (Boston, USA), DuP-697 was purchased from Tocris Bioscience. All medium, solution and enzymes for cell culture were purchased from Sigma Aldrich.

\section{Cell culture}

Colon cancer cells HT29 were purchased from the Sap Institute (The Ministry of Food, Agriculture and Livestock, Ankara, Turkey). Cells were proliferated in continuous passages, frozen in aliquots and stored in liquid nitrogen. The cells were kept in DMEM with phenol red and NaHCO3. Heat inactivated FBS $10 \%$, penicillin and streptomycin $1 \%$ added as supplement into the culture medium. Cells were grown in cell culture flasks $\left(\mathrm{T}-75 \mathrm{~cm}^{2}\right)$ in a humidified atmosphere containing $5 \% \mathrm{CO}_{2}$ at $37^{\circ} \mathrm{C}$.

\section{Instrumentation}

xCELLigence system: The xCELLigence system was used according to the instructions of the supplier (Roche Applied Science and ACEA Biosciences, 2008). The xCELLigence system has 4 major components: the RTCA analyzer, the RTCA DP station, the RTCA computer with software, and disposable E-plate 16. The major difference of xCELLigence system from other cytotoxicity determining systems is the E-plate 16: This plate is very similar to regular 96 well plate. However the E-plate 16 differs from standard 96-well plates with its incorporated gold cell sensor arrays in the bottom, which contributes cells in-side each well to be monitored and assayed. Sensor electrodes are capable to monitoring and detection of changes of the cells on the electrodes. The voltage applied to the electrodes during RTCA measurement is about $20 \mathrm{mV}$ (RMS). In the absence of cells, ion ingredient of the cell culture medium determines the impedance. In the presence of cells, cells attached to the electrode cause an increase in impedance. Thus, the more cells that are growing on the electrodes, the larger the value of electrode impedance. The RTCA associated software allows users to obtain parameters such as: average value, maximum and minimum values, standard deviation (SD), half maximum effect of concentration (EC50), half maximum inhibition of concentration (IC50), cell index (CI), and in addition graphics. (Roche Applied Science and ACEA Biosciences, 2008).

Cell growth and proliferation assay using xCELLigence system: HT 29 cells were grown and expanded in tissueculture flasks. After reaching $75 \%$ confluence, the HT29s were washed with PBS, then detached from the flasks by a short treatment with trypsin/EDTA. Then after, $100 \mu \mathrm{L}$ of medium mixture at room temperature was added into each well of E-plate 16. After this the E-plate 16 was connected to the system and the background electrical activity of cells were measured. In the meantime, the cells 
Multikinase Inhibitor Motesanib Effects Alone and Combined with a Selective COX-2 Inhibitor in Colorectal Cancer Cells

were re-suspended in cell culture medium and adjusted to 400.000 cells $/ \mathrm{mL} .100 \mu \mathrm{L}$ of cell suspension was added to the $100 \mu \mathrm{L}$ medium containing wells on E-plate16. After 30 min incubation at room temperature, E-plate 16 was placed into the cell culture incubator. Finally, proliferation of the cells was monitored every hour for a period of up to $72 \mathrm{~h}$ via the incorporated sensor electrode arrays of the E-Plate 16. The electrical impedance was measured by the RTCA-integrated software of the xCELLigence system as a dimensionless parameter termed CI.

Cytotoxicity assay using xCELLigence system: First of all, the optimal starting concentration for proliferation experiments of the HT29 was defined. After seeding the different amount of cells in $100 \mu \mathrm{L}$ medium to each well of the E-plate16, the proliferation of the cells was observed every $30 \mathrm{~min}$ by the xCELLigence system. Approximately $18 \mathrm{~h}$ after seeding, cells reached to the log growth phase. At that point, the cells were exposed to $10 \mu \mathrm{L}$ of medium containing the motesanib $(100,50,25,12.5$ and 6.25 $\mathrm{nM} /$ well) both alone and in combination with DuP-697 (50 and $25 \mathrm{nM} /$ well). Controls received either medium only, or medium + motesanib or medium + DuP-697. All experiments were run for $72 \mathrm{~h}$.

Angiogenesis assay using chorioallantoic membrane (CAM) assay

Preparation of the pellets: In order to form a round shaped pellet motesanib and DuP-697 were dissolved in water in appropriate concentration and mixed with agarose. The agarose (Merck, Damstadt, Germany) is added to distilled water to obtain a $2.5 \%(\mathrm{w} / \mathrm{v})$ solution. This solution is put into the autoclave in $121^{\circ} \mathrm{C}$ and under 1 atmospheric pressure to provide dissolution and sterilization. Next, it is left in the room temperature and let to go down up to $37^{\circ} \mathrm{C}$. Drugs added after it has been cooled down. Appropriate volumes of solutions were used to achieve three different concentrations of motesanib and DuP-697 (100 nM, $10 \mathrm{nM}$ and $1 \mathrm{nM}$ per $10 \mu \mathrm{l}$ pellet). Approximately one hundred pellets for each study set are used. Therefore, approximately $1 \mathrm{ml}$ of combined agar and drug solution $(10 \mu \mathrm{l} \times 100=1 \mathrm{ml})$ was prepared initially for motesanib and DuP-697. The drug solutions with $10 \mathrm{nM}$ and $1 \mathrm{nM}$ concentrations were prepared by diluting these initial mixtures ten folds with the agarose solution again. Using a micropipette, $10 \mu \mathrm{l}$ drops of this mixed solution were placed on previously sterilized, vertical, cylindrical stainless steel rods which were $5 \mathrm{~mm}$ in diameters to obtain circular pellets with the same diameter. The pellets were then let to be solidified at room temperature in a sterile setting.

Chicken chorioallantoic membrane (CAM) assay: Ross 308 strain fertilized hens' eggs were purchased from Yemsel Poultry Company (Kayseri, Turkey). The study protocol was approved by the Cumhuriyet University Animal Ethics Committee. The fertilized hens' eggs were incubated in horizontal position with environmental conditions of $37.5^{\circ} \mathrm{C}$ temperature and $80 \%$ relative humidity. On the fifth day of the incubation, $5 \mathrm{ml}$ of albumen was removed from the egg with a syringe (Figure 1A) and a shell piece of $2-3 \mathrm{~cm}$ in diameter was taken away from the contrary side of the eggs. Normal development of the CAM was observed and verified (Figure 1B) and malformed or dead embryos were excluded. The windows on the egg shells were sealed with gelatin and thereafter, the eggs were incubated for 72 more hours to have CAM reaching $2 \mathrm{~cm}$ in diameter. Subsequently (on day 8), the seal was removed and the pellets were put on the chorioallantoic membrane of each egg (Figure 1C). The seal was re-placed and the eggs were then incubated for another 24 hours. The angiogenesis has been evaluated after that period. For each concentration of drug, twenty eggs have been used. Pellets containing just agar have been used as the negative control group. Pellets containing bevacizumab, FDA approved antiangiogenic agent, have been used as the positive control group. All the tests has been performed twice. The eggs in which the pellets caused inflammation and embryo toxicity were excluded.

Angiogenesis scoring: The antiangiogenic effect of our drugs in chorioallantoic membrane were evaluated under a stereoscopic microscope and the assessment is made according to the scoring system used previously in several studies (Bürgermeister, 2002; Demirci 2003). In Bürgermeister's scoring system, the change in the density of the capillaries around the pellet and the extent of the effect are evaluated (Figure 1D). The pellets were evaluated as; score 0 showed the absence of any demonstrable antiangiogenic effect (normal embryo and no difference in surrounding capillaries); score 0.5 represented a very weak (no capillary-free area but an area with reduced density of capillaries which is not larger than the pellet area), score 1 a weak moderate (a small capillaryfree area or a small area with significantly decreased density of capillaries; less than double the size of the pellet is involved), and score 2 a strong antiangiogenic effect (a capillary free area around the pellet which is equal to or more than double the size of the pellet itself). The equation used for the determination of the average score was as follows: Average score $=[$ Number of eggs (Score 2) $\times 2+$ Egg number $($ Score 1$) \times 1] /$ [Total number of eggs (Score 0,1,2)].

According to this scoring system, a score of $<0.5$ meant that there was no antiangiogenic effect; a score of 0.5 to 1 indicated a weak antiangiogenic effect, and a score of $>1$ implied a strong antiangiogenic effect.

\section{Detectation of apoptosis by annexin $v$ method}

Apoptotic cell death was tested using a flouresin isothiocynate (FITC)-conjugated Annexin V/PI assay kit by flow cytometry. Briefly, 5x105 cells were washed with ice cold PBS, re-suspended in $100 \mathrm{ml}$ binding buffer, and stained with $5 \mathrm{ml}$ of FITC conjugated Annexin V $(10 \mathrm{mg} / \mathrm{ml})$ and $10 \mathrm{ml}$ of PI $(50 \mathrm{mg} / \mathrm{ml})$. The cells were incubated for $15 \mathrm{~min}$ at room temperature in the dark. After incubating period $400 \mathrm{ml}$ of binding buffer was added to the cell suspension. Finally cells were analyzed by flow cytometry device (FACScan, Becton- Dickinson, USA). The HT29 cells were gated separately according to their granularity and size on forward scatter (FSC) versus Side Scatter (SSC) plots. Early and late apoptosis was evaluated on fluorescence 2 (FL2 for propidium iodide) versus fluorescence 1 (FL1 for Annexin) plots. Cells stained with only annexin $\mathrm{V}$ were evaluated as being in 
Tijen Temiz Kay et al

early apoptosis; cells stained with both annexin V and propidium iodide were evaluated as being in late apoptosis or in a necrotic stage.

\section{Statistical analysis}

The scores of angiogenesis were compared with Kruskal-Wallis ANOVA test and Mann-Whitney U test. A p value of less than 0.05 was considered as statistically significant.

\section{Results}

Monitoring dynamic cell proliferation and attachment in real-time using xCELLigence system

First of all the optimal concentration has been determined for cell multiplying and viability measurements. For this purpose $100.000,50.000,25.000,12.500,6.250$, 3.125 and 1.562 cells/well were placed in the E-Plate 16 and the impedance was measured. After getting the result of this experiment, we concluded that 50.000 cells/well experiments reflect cell cycle effects best. After this part of the study all wells were seeded with 40.000 cells/well.

\section{Monitoring of cytotoxicity in real-time using xCELLigence system}

We used the 40,000 cells/well concentration in the xCELLigence assay to examine the anti-proliferative effects elicited by motesanib, as the 40,000 cells/well concentration which has an optimal treatment window between 16-24 hours. Motesanib caused concentration dependent cytotoxic effect on HT29 colorectal cancer cells. At $50 \mathrm{nM}$ concentration of motesanib has shown complete cytotoxic effect and decreased CI to 0.2. At $25 \mathrm{nM}$ concentration of motesanib elicited partial cytotoxic effect and decreased CI to 1.2. At 50 and 25 $\mathrm{nM}$ concentrations of motesanib showed statistically significant cytotoxic effect when compared to the control $(\mathrm{p}<0.05)$, but significant cytotoxic effect has not been observed at $12.5 \mathrm{nM}$ concentration (Figure 2A).

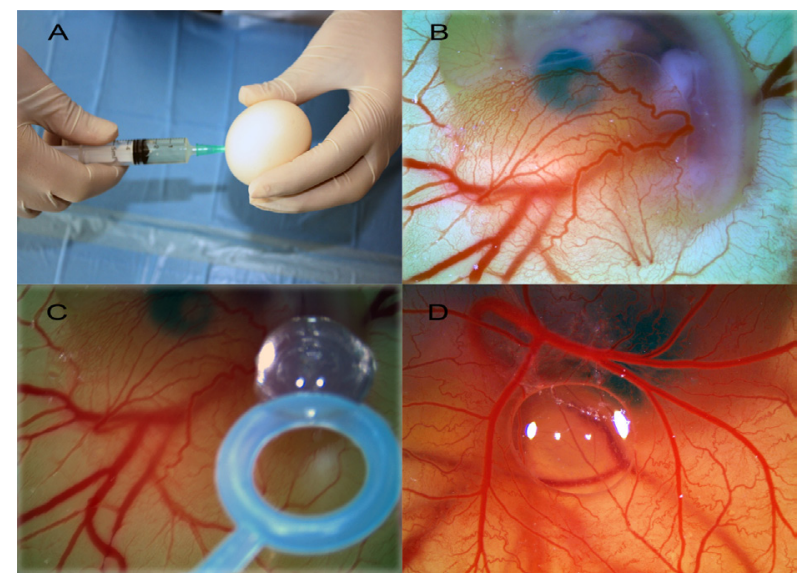

Figure 1. A. Albumen is removed with a syringe. $B$. The appearance of the chorioallantoic membrane (CAM) through a window on the egg shell (x8). C. The placement of the pellet on the CAM (x8). D. Inhibiton of the capillaries on the CAM (score:1) by the drug (x8). 247x247mm (300x300 DPI)
Twenty-four hours after treatment with motesanib, an inhibitor concentration 50 value of $\left(\mathrm{IC}_{50}\right) 6.21 \times 10-9 \mathrm{M}$ was achieved.

In order to determine interaction between motesanib and DuP-697, $25 \mathrm{nM}$ motesanib was combined with 25 nM DuP. The partially effective cytotoxic dose of DuP697 was chosen according to the results in our recently reported study (Altun et al., 2014). Combination of Motesanib+DuP caused complete cytotoxic effect on HT29 cells when compared to the motesanib $25 \mathrm{nM}$ alone $(\mathrm{p}<0.05)$ (Figure 2B). The CI of motesanib 25+DuP $25 \mathrm{nM}$ was significantly low when compared to the motesanib 25 $\mathrm{nM}$ alone $(\mathrm{p}<0.05)$ (Figure $2 \mathrm{~B})$.

Determining antiangiogenic effects of motesanib and DuP alone and in combination

The eggs which were in the negative control group (pellet with no drug) demonstrated no significant antiangiogenic effect (average antiangiogenic score $=0.2$ ). All the study drugs demonstrated diverse antiangiogenic effects when compared to the negative control $(\mathrm{p}<0.05)$. Figure 3 shows the antiangiogenic scores of motesanib, DuP-697 and motesanib+DuP-697 in 100, 10 and $1 \mathrm{nM}$ concentrations. Antiangiogenic scores of motesanib were 1.4, 1.2 and 0.9 , respectively. These scores show that motesanib caused concentration dependent antiangiogenic effect on CAM. As shown in the scatter graph, there was statistically significant difference between 100 $\mathrm{nM}$ and $1 \mathrm{nM}$ concentrations of motesanib $(\mathrm{p}<0.05)$ (Figure 3). Similarly, DuP-697 in 100, 10 and $1 \mathrm{nM}$ concentrations caused antiangiogenic effect (Figure 3). The antiangiogenic scores of DuP-697 were 1.2, 0.8 and 0.5 , respectively. The antiangiogenic score with the $100 \mathrm{nM}$ of DuP-697 was significantly higher than $1 \mathrm{nM}$ $(p<0.05)$ (Figure 3). In order to see if there is an interaction between motesanib and DuP-697, these agents were combined in $50+50,5+5$ and $0.5+0.5 \mathrm{nM}$ concentrations. The antiangiogenic scores of combination were 1.7, 1.6 and 1.1, respectively (Figure 3). The antiangiogenic scores of motesanib+DuP-697 50+50 nM were significantly high

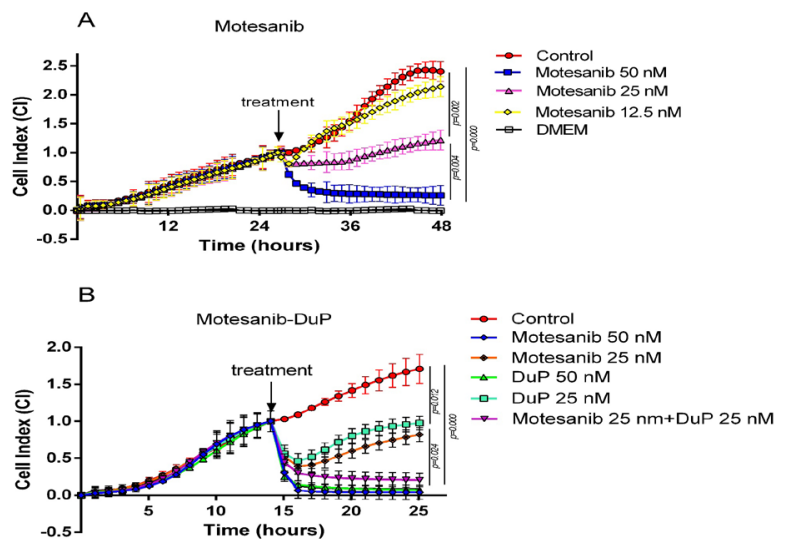

Figure 2. A. Real-time monitoring of cytotoxic effect of Motesanib on HT29 colorectal cancer cells using RTCA. B. Real-time monitoring of cytotoxic effect of Motesanib-DuP-697 combination on HT29 colorectal cancer cells using RTCA 


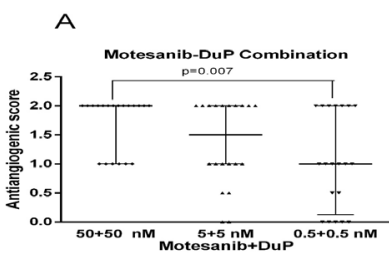

B
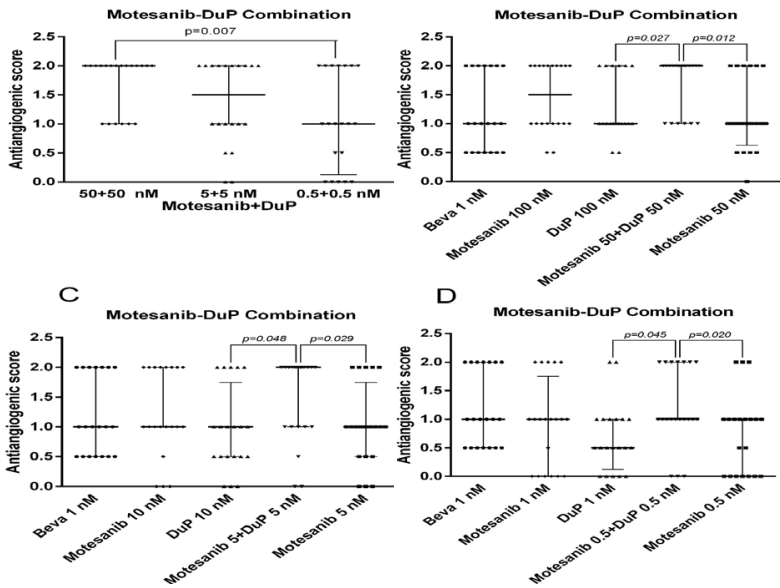

Figure 3. The Antiangiogenic Scores of Motesanib and DuP-697 alone and in Combination. A) Motesanib + DuP697 50+50, 5+5, 0.5+0.5 nM, B) Motesanib 100, DuP-697 100, Motesanib+ DuP-697 50+50 nM, C) Motesanib 10, DuP-697 10, Motesanib+ DuP-697 5+5 nM, D) Motesanib 1, DuP-697 1 , Motesanib+ DuP-697 0.5+0.5 nM, Beva (bevacizumab) is a positive control as stated in method

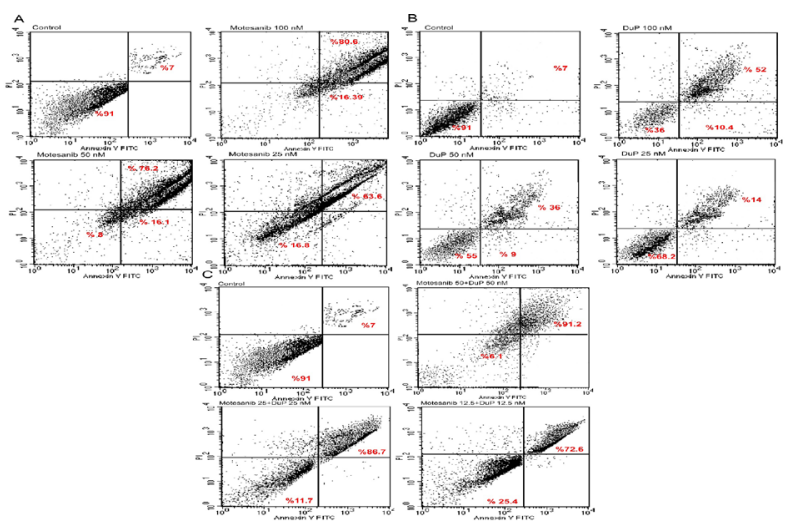

Figure 4. A) Dot plot distribution of live, preapoptotic and apoptotic cells after administration of motesanib alone, B) Dot plot distribution of live, preapoptotic and apoptotic cells after administration of DuP-697 alone, C) Dot plot distribution of live, preapoptotic and apoptotic cells after administration of motesanib and DuP-697 combination

when compared to the scores of DuP-697 $100 \mathrm{nM}$ alone and there was no significant difference when compared to motesanib $100 \mathrm{nM}$ alone $(\mathrm{p}<0.05)$ (Figure 3$)$. Similar results were observed when lower concentrations of motesanib and DuP were combined. The antiangiogenic scores of combinations of motesanib+DuP- $6975+5$ or $0.5+0.5 \mathrm{nM}$ were significantly high when compared to the scores of DuP-697 10 or $1 \mathrm{nM}$, but there was no significant difference when compared to motesanib 10 or $1 \mathrm{nM}(\mathrm{p}<0.05)$ (Figure 3).

Determining apoptototic effects of motesanib and DuP alone and in combination

The apoptosis induction was assessed by Annexin V-FITC assay. In the dot plot of flow cytometric analysis (Figure 4), the lower-right (LR) area was the Annexin

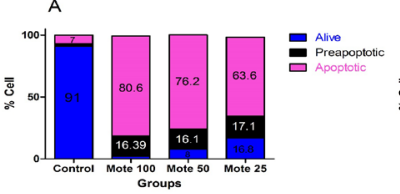

$\mathrm{B}$

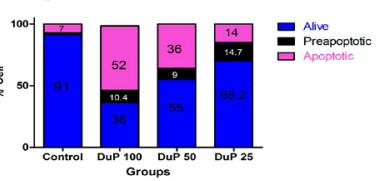
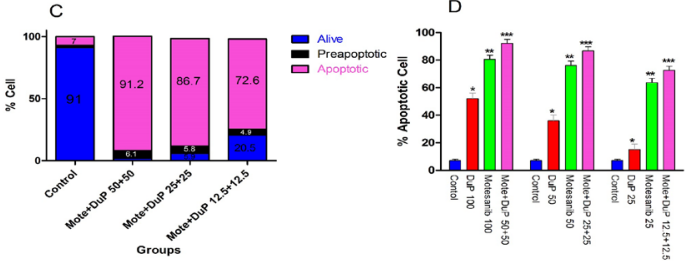

Figure 5. Distribution of live, preapoptotic and apoptotic cells after administration of A) Motesanib alone; B) DuP-697 alone; C) Motesanib and DuP-697 combination; and D) Comparison of apoptotic cell percentage of alone and combination administrations

$\mathrm{V}$ positive/ PI negative portion which represented the preapoptotic fraction, the upper-right (UR) area was the Annexin V positive/ PI positive portion which represented the apoptotic fraction. The percentage of UR (apoptosis portion) area increased gradually according to the concentration of motesanib from $7 \%$ in control group to $80.6 \%, 76.2 \%$ and $63.6 \%$ in motesanib group (in 100,50 and $25 \mathrm{nM}$ concentrations) respectively $(\mathrm{p}<0.05)$ (Figure 4). Combinations of motesanib+DuP-697 50+50, 25+25 and $12.5+12.5 \mathrm{nM}$ caused significantly higher apoptotic effect $(\% 91.2,86.7$ and 72.6$)$ when compared to apoptotic effect of all concentrations of motesanib alone $(p<0.05)$ (Figure 5).

\section{Discussion}

Colorectal cancer is one of the leading causes of death in many developed countries and the number of patients suffering from colon cancer has increased in the last years. The 5-year survival rate of metastatic CRC is below 10\%, thus it is essential to understand the molecular and cellular biology supporting the drug resistance and there is need to develop effective therapy to improve this deadly disease (Paviva et al, 2015).

In current therapeutic approaches for cancer, multitargeting drugs or combinations of drugs which target multiple cell signaling pathways are attractive as cancer is a disease occurring by multiple signaling pathways. These pathways can include more than 500 genes and some can serve as targets to develop anticancer therapies (Gupta et al, 2011; Tan et al, 2014). Inhibiting a single signaling pathway may maintain temporary responses, but for many instances it is ineffective.

Targeted therapies which aim to inhibit molecular pathways that are of great importance for tumor growth have expanded in the last 15-20 years. New targeted agents, i.e., monoclonal antibodies, fusion proteins and small molecule inhibitors have been developed and are being used clinically. Anticancer activity of targeted agents such as tyrosine kinase inhibitors is different from traditional chemotherapeutic agents as their activity originates from anti-angiogenesis or the inhibition of growth signals. These targeted agents increase antitumor 
activity when used in combination with chemotherapy (Dal Lago et al., 2008; Popov et al., 2008).

One of the approaches in cancer therapy has been targeting angiogenesis. Investigators have focused on anti-angiogenic strategies aiming to decrease tumor blood vessel density in order to inhibit tumor growth. VEGF activates the angiogenic switch and increases vascular permeability. It is a potent mitogen for endothelial cells that binds to three tyrosine kinase receptors, known as VEGFR-1, -2 and -3. VEGFR-1 and -2 are present on endothelial cells and VEGFR-3 is present on lymphatic endothelial cells. For endothelial cell permeability, differentiation and proliferation; VEGFR-2 is the dominant signaling receptor. Binding of VEGF to its receptor VEGFR-2, enhances the expression of malignant phenotypes. Therefore VEGF inhibitors may be useful to provide a balance between pro- and antiangiogenic cytokines and tumor vessels (Riaz et al, 2015). Bevacizumab which is a humanized monoclonal antibody is a good example for VEGF inhibitors. Bevacizumab downregulates angiogenesis by inhibiting the binding of VEGF to its receptors. It has been approved by United States Food and Drug Administration and it is used for the treatment of many solid tumors, including CRC (Zhu et al, 2014; Dusetzina et al., 2015).

Cyclooxygenase- 2 is the inducible form of cyclooxygenase that belongs to the myeloperoxidase family and response to mitogenic and proinflammatory responses it catalysis the conversion of arachidonic acid to prostaglandins. During the chemical metabolism of arachidonic acid in many situations reactive metabolites form and these metabolites have mutagenic and carcinogenic activity. Pro-inflammatory cytokines, growth factors, bile acids, ultraviolet $B$ irradiation are stimulators of COX-2 expression. Cyclooxygenase-2 contributes to disease processes, including cancer and inflammation (Kim et al, 2011; Tu et al., 2014). Cyclooxygenase can convert pro-carcinogens to carcinogens and can co-oxidase xenobiotics into mutagens by its peroxidase activity. The COX-2 derived PGE2 is an important downstream effector of COX-2. Prostaglandin E2 can promote tumorigenic processes including invasion, metastasis, apoptosis and immune function. Previous studies support the casual role of COX-2 in tumor promotion in CRC models and provide evidence that COX-2 plays a key role in carcinogenesis and that COX-2 inhibitors can be a class of therapeutic agents for CRC therapy (Ng et al., 2014; Wu and Sun, 2015). Oshima et al., determined that treating APC Delta 716 knockout mice with selective COX 2 inhibitor reduces the number of intestinal polyps and this was significant when compared to non-selective COX inhibitor sulindac (Oshima et al., 1996).

Combination therapy with VEGF inhibitors and COX2 can be a rationale therapy to improve anti-cancer efficacy. As both PEG2 and EGRF receptor activation inhibits apoptosis by stimulating the P13kinase/Akt pathway, they act synergistically. There is cross stimulation as PGE2 stimulates EGFR signaling while, EGRF transactivation stimulates COX2, in this way PGE2 expression (Ghosh et al., 2010). Recently we reported that DuP-697, a selective COX-2 inhibitor induces antiproliferative, antiangiogenic and apoptotic effects on HT29 CRC cells (Altun et al., 2014) and the combination of DuP-697 with E7080, a multi-targeted kinase inhibitor shows stronger effects. The combined use of two drugs produced synergistic effects. In the present study, we determined the effects of motesanib, a multikinase inhibitor both alone and in combination with DuP-697 on cell proliferation, apoptosis and, angiogenesis in human HT29 colorectal cancer cell lines.

Motesanib; chemical structure as follows $\mathrm{N}-$ (2, 3-dihydro-3, 3-dimethyl-1H-indol-6-yl)-2-[(4pyridinylmethyl) amino]-3-pyridinecarboxamide, is a multi-target tyrosine kinase inhibitor. As an angiogenesis inhibitor motesanib has clinical advantage with more complete inhibition of VEGF targets compared to bevacizumab which selectively blocks VEGF A. It is also an inhibitor of PDGFR and c-Kit (Coxon et al., 2009). Motesanib, has been reported to inhibit a variety of tumor types as monotherapy and in combination with chemotherapy by suppressing cell proliferation and angiogenesis (Coxon et al., 2009; Rosen et al., 2009; Blumenschein et al., 2011; Schilder et al., 2013). Recently, a phase $1 \mathrm{~b}$ study has been performed to determine the safety and efficacy of motesanib alone or combined with panitumumab plus chemotherapy in patients with metastatic CRC (Tebbutt et al., 2015). In the present study, motesanib showed a potent action by mediating HT29 cell growth inhibition, angiogenesis inhibition and inducing apoptosis. We found that motesanib inhibited cell proliferation in concentration dependent manner with 6.21x 10-9 IC50. CAM assay showed that Motesanib also inhibited angiogenesis in a dose dependent manner. Antiangiogenic scores of motesanib were 1.4, 1.2 and 0.9 at 100,10 and $1 \mathrm{nM}$ concentrations. Flow cytometric analysis showed that motesanib caused apoptotic effect at 100,50 and $25 \mathrm{nM}$ concentrations.

DuP-697 (5-bromo-2-(4-fluorophenyl)-3[4-(methylsulfonyl) phenyl]-thiophene), is a slow, time dependent selective COX-2 inhibitor and it is a member of the vicinal diaryl heterocycles like other selective agents, rofecoxib and celecoxib which are currently used in clinical practice. The exact mechanism of how COX-2 inhibitors show anti-tumor effect is currently not known. Some studies suggest that the anti-proliferative effect of DuP-697 may be exerted via the induction of apoptosis and that this was associated with up-regulation of caspases 3 , 8 and 9 (Peng et al., 2008; Agarwal et al., 2013).

In the present study we combined motesanib with low concentrations of DuP-697. Combination caused strong cytotoxic effect on HT29 cells. The combination of the two drugs significantly reduced the proliferation, migration and invasion of HT29 cells in vitro. Antiangiogenic scores (1.7, 1.6 and 1.1, respectively) of combination of motesanib+ DuP-697 were high when compared to the scores of motesanib alone. These results show that combination of motesanib+DuP-697 is more potent in the inhibition of angiogenesis. This effect also contributes to its antitumor activities. Moreover, our results confirm that the growth inhibiting effect is mediated through arrest of cell-cycle progression. Apoptotic effect of combinations of motesanib+Dup-697 (\%91.2, 86.7 and 72.6) were significantly higher when compared to 
Multikinase Inhibitor Motesanib Effects Alone and Combined with a Selective COX-2 Inhibitor in Colorectal Cancer Cells

apoptotic effect of motesanib alone in all concentrations. The enhanced anticancer effects of the combination of motesanib+Dup-697, may be partially COX-2 independent and mediated through various factors like reduced expression of VEGF, PEG2 production in vitro and activation of apoptosis pathway. The present study demonstrates that motesanib, a multikinase inhibitor has antiproliferative, antiangiogenic and apoptotic effects on HT29 colorectal cancer cells. Additionally, the combination of motesanib with DuP-697 significantly increases these effects. The present study indicates that combining multikinase inhibitors with COX-2 inhibitors may enable to use these inhibitors in lower concentrations. Using multikinase inhibitors in lower concentrations may prevent resistance to these drugs and also combinations with lower concentrations can reduce side effects. Detailed in vitro and in vivo studies are required to confirm the synergistic growth inhibition, antiangiogenic and apoptotic activity of the two drugs combination.

\section{Acknowledgements}

This study was supported by Cumhuriyet University Scientific Research Project T-468 (CUBAP, Sivas, Turkey).

\section{References}

Agarwal V, Hodgkinson VC, Eagle GL, et al (2013). Proteomic (antibody microarray) exploration of the molecular mechanism of action of the specific COX-2 inhibitor DuP 697. Int J Oncol, 42, 1088-92.

Altun A, Turgut NH, Kaya TT (2014).Anticancer effect of COX2 inhibitor DuP-697 alone and in combination with tyrosine kinase inhibitor (E7080) on colon cancer cell lines. Asian Pac J Cancer Prev, 15, 3113-21.

Bestas R, Kaplan MA, Isikdoğan A (2014). The correlation between serum VEGF levels and known prognostic risk factors in colorectal carcinoma. Hepatogastroenterol, 61, 267-71.

Agarwal V, Hodgkinson VC, Eagle GL, et al (2013). Proteomic (antibody microarray) exploration of the molecular mechanism of action of the specific COX-2 inhibitor DuP 697. Int J Oncol, 42, 1088-92.

Blumenschein GR Jr, Kabbinavar F, Menon H, et al (2011). Motesanib NSCLC Phase II Study Investigators. A phase II, multicenter, open-label randomized study of motesanib or bevacizumab in combination with paclitaxel and carboplatin for advanced nonsquamous non-small-cell lung cancer. Ann Oncol, 22, 2057-67.

Bürgermeister J, Paper DH, Vogl H, et al. (2002) LAPSvS1, a $(1 \rightarrow 3)$-betagalactan sulfate and its effect on angiogenesis in vitro andin vivo. Carbohydr Res, 337, 1459-66.

Cathcart MC, O’Byrne KJ, Reynolds JV, O'Sullivan J, Pidgeon GP (2012). COX-derived prostanoid pathways in gastrointestinal cancer development and progression: novel targets for prevention and intervention. Biochim Biophys Acta, 1825, 49-63.

Center M.M, Jemal A, Ward E (2009). International trends in colorectal cancer incidence rates. Cancer Epidemiol Biomarkers Prev, 18, 1688-94.

Chu E (2012). An update on the current and emerging targeted agents in metastatic colorectal. Cancer, 11, 1-13.

Chu J, Lloyd FL, Trifan OC, Knapp B, Rizzo MT (2003).
Potential involvement of the cyclooxygenase- 2 pathway in the regulation of tumor-associated angiogenesis and growth in pancreatic cancer. Mol Cancer Ther, 2, 1-7.

Coxon A, Bush T, Saffran D, et al (2009). Broad antitumor activity in breast cancer xenografts by motesanib, a highly selective, oral inhibitor of vascular endothelial growth factor, platelet-derived growth factor, and Kit receptors. Clin Cancer Res, 15, 110-8.

Coxon A, Ziegler B, Kaufman S, et al (2012) a. Antitumor activity of motesanib alone and in combination with cisplatin or docetaxel in multiple human non-small-cell lung cancer xenograft models. Mol Cancer, 11, 70 .

Coxon A, Bready J, Kaufman S, et al (2012) b. Anti-tumor activity of motesanib in a medullary thyroid cancer model. $J$ Endocrinol Invest, 35, 181-90.

Cui Y, Deming-Halverson SL, Shrubsole MJ, et al (2014). Use of nonsteroidal anti-inflammatory drugs and reduced breast cancer risk among overweight women. Breast Cancer Res Treat, 146, 439-46

De Boer RH, Kotasek D, White S, et al (2012). Phase 1b dosefinding study of motesanib with docetaxel or paclitaxel in patients with metastatic breast cancer. Breast Cancer Res Treat, 135, 241-52.

Demirci B, Dadandi MY, Paper DH, et al (2003). Chemical composition of the essential oil of Phlomis linearis Boiss.\&Bal., and biologicaleffects on the CAM assay: a safety evaluation. $Z$ Naturforsch $C, \mathbf{5 8}, 826-9$.

Hohla F, Winder T, Greil R, et al 2014. Targeted therapy in advanced metastatic colorectal cancer: current concepts and perspectives. World J Gastroenterol, 20, 6102-12.

Kim BH, Kim CI, Chang HS, et al (2011). Cyclooxygenase-2 overexpression in chronic inflammation associated with benign prostatic hyperplasia: is it related to apoptosis and angiogenesis of prostate cancer? Korean J Urol, 52, 253-9.

Kim JY, Chung SW, Kim SY, Byun Y (2015). Enhanced AntiAngiogenic Effect of Low Molecular Weight Heparin-Bile Acid Conjugates by Co-Administration of a Selective COX2 Inhibitor. Pharm Res, 32, 2318-27.

Li M, Tan SY, Wang XF (2014). Paeonol exerts an anticancer effect on human colorectal cancer cells through inhibition of PGE $\geq$ synthesis and COX-2 expression. Oncol Rep, 32, 2845-53.

Lu JF, Claret L, Sutjandra L et al (2010).Population pharmacokinetic/pharmacodynamic modeling for the time course of tumor shrinkage by motesanib in thyroid cancer patients. Cancer Chemother Pharmacol, 66, 1151-8

Ma L, del Soldato P, Wallace JL (2002). Divergent effects of new cyclooxygenase inhibitors on gastric ulcer healing: Shifting the angiogenic balance. Proc Natl Acad Sci US A. 99, 13243-7.

Ninomiya I, Nagai N, Oyama K, et al (2012). Antitumor and anti-metastatic effects of cyclooxygenase-2 inhibition by celecoxib on human colorectal carcinoma xenografts in nude mouse rectum. Oncol Rep, 28, 777-84.

Ohno S, Ohno Y, Suzuki N, Soma G, Inoue M (2007). Cyclooxygenase-2 expression correlates with apoptosis and angiogenesis in endometrial cancer tissue. Anticancer Res, 27, 3765-70.

Paudyal B, Paudyal P, Shah D, et al (2014). Detection of vascular endothelial growth factor in colon cancer xenografts using bevacizumab based near infrared fluorophore conjugate. $J$ Biomed Sci, 21, 35.

Roche Diagnostics GmbH (2008). Introduction of the RTCA SPInstrument. RTCA SP Instrument Operator's Manual, A. Acea Biosciences, 2008, 14-6.

Qiu ZQ, Qiu ZR (2015). Sensitivity of gastric cancer cells to chemotherapy drugs in elderly patients and its correlation 
Tijen Temiz Kay et al

with cyclooxygenase-2 expression. Asian Pac J Cancer Prev, 16, 3447-50.

Peng HL, Zhang GS, Liu JH, Gong FJ, Li RJ (2008).Dup-697, a specific COX-2 inhibitor, suppresses growth and induces apoptosis on K562 leukemia cells by cell-cycle arrest and caspase-8 activation. Ann Hematol, 87, 121-9.

Riaz SK, Iqbal Y, Malik MF (2015). Diagnostic and therapeutic implications of the vascular endothelial growth factor family in cancer. Asian Pac J Cancer Prev, 16, 1677-82.

Rosen LS, Kurzrock R, Mulay M, et al (2007). Safety, pharmacokinetics, and efficacy of AMG 706, an oral multikinase inhibitor, in patients with advanced solid tumors. $J$ Clin Oncol, 25, 2369-76.

Saleem TH, Attya AM, Ahmed EA, et al (2015). Possible Protective Effects of Quercetin and Sodium Gluconate Against Colon Cancer Induction by Dimethylhydrazine in Mice. Asian Pac J Cancer Prev, 16, 5823-8.

Salimi M, Esfahani M, Habibzadeh N, et al (2012). Change in nicotine-induced VEGF, PGE2 AND COX-2 expression following COX inhibition in human oral squamous cancer. $J$ Environ Pathol Toxicol Oncol, 31, 349-56.

Salinas CA, Kwon EM, FitzGerald LM, et al (2010). Use of aspirin and other nonsteroidal antiinflammatory medications in relation to prostate cancer risk. Am J Epidemiol, 172, 578-90.

Saraiva AL, Payan-Carreira R, Gartner F, et al (2015). Immunohistochemical expression of cyclooxygenase-2 (COX-2) in feline endometrial adenocarcinoma and in normal and hyperplastic endometria. Reprod Domest Anim, 50, 333-40.

Schilder RJ, Sill MW, Lankes HA, et al (2013). A phase II evaluation of motesanib (AMG 706) in the treatment of persistent or recurrent ovarian, fallopian tube and primary peritoneal carcinomas: a Gynecologic Oncology Group study. Gynecol Oncol, 129, 86-91.

Steinbach G, Lynch PM, Phillips RK, et al (2000). The effect of celecoxib, a cyclooxygenase- 2 inhibitor, in familial adenomatous polyposis. N Engl J Med, 342, 1946-52.

Shimizu K, Yukawa T, Okita R, et al (2015). Cyclooxygenase-2 expression is a prognostic biomarker for non-small cell lung cancer patients treated with adjuvant platinum-based chemotherapy. World J Surg Oncol, 13, 21.

Tan HK, Moad AI, Tan ML (2014). The mTOR signalling pathway in cancer and the potential mTOR inhibitory activities of natural phytochemicals. Asian Pac J Cancer Prev, 15, 6463-75.

Tebbutt N, Kotasek D, Burris HA, et al (2015). Motesanib with or without panitumumab plus FOLFIRI or FOLFOX for the treatment of metastatic colorectal cancer. Cancer Chemother Pharmacol, 75, 993-1004.

Tu B, Ma TT, Peng XQ, et al (2014). Targeting of COX-2 expression by recombinant adenovirus shRNA attenuates the malignant biological behavior of breast cancer cells. Asian Pac J Cancer Prev, 15, 8829-36.

van de Velde CJ, Boelens PG, Tanis PJ, et al (2014). Experts reviews of the multidisciplinary consensus conference colon and rectal cancer 2012: science, opinions and experiences from the experts of surgery. Eur J Surg Oncol, 40, 454-68.

Wei D, Wang L, He Y, et al (2004). Celecoxib inhibits vascular endothelial growth factor expression in and reduces angiogenesis and metastasis of human pancreatic cancer via suppression of $\mathrm{Sp} 1$ transcription factor activity. Cancer Res, 64, 2030-8.

Wong VW, Chan FK (2007). Aspirin reduced the incidence of colorectal cancer during 23-year follow-up in healthy men or patients with recent TIA. ACP J Club, 147, 72 .

Yazawa K, Tsuno NH, Kitayama J, et al (2005). Selective inhibition of cyclooxygenase (COX)-2 inhibits endothelial cell proliferation by induction of cell cycle arrest. Int $J$ Cancer, 113, 541-8.

Zhu LM, Zhao YZ, Ju HX, et al (2014). Efficacy and safety of bevacizumab in Chinese patients with metastatic colorectal cancer. Asian Pac J Cancer Prev, 15, 6559-64. 